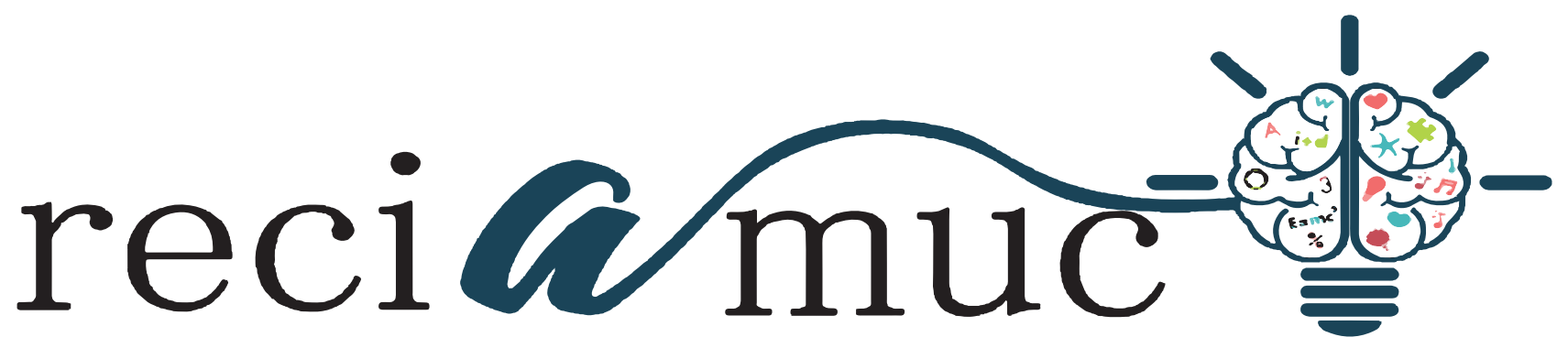

DOl: 10.26820/reciamuc/4.(3).julio.2020.167-182

URL: https://reciamuc.com/index.php/RECIAMUC/article/view/511

EDITORIAL: Saberes del Conocimiento

REVISTA: RECIAMUC

ISSN: 2588-0748

TIPO DE INVESTIGACIÓN: Artículo de Revisión

CÓDIGO UNESCO: 5307.09 Teoría de la Planificación Económica

PAGINAS: 167-182

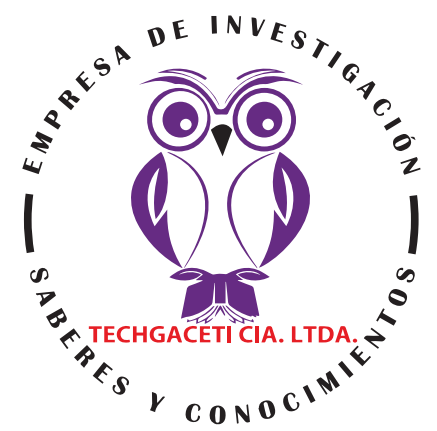

\title{
Planificación estratégica y su impacto ante la crisis del Covid-19
}

Strategic planning and its impact in the face of the Covid-19 crisis Planejamento estratégico e seu impacto em face da crise da Covid-19 Washington Enrique Pazmiño Gavilánez'; Verónica Alexandra Merchán Jacome²; Eduardo Higinio Jiménez Rendon ${ }^{3}$

RECIBIDO: 20/05/2020 ACEPTADO: 19/07/2020 PUBLICADO: 30/07/2020

1. Magister Ejecutivo en Dirección de Empresas con énfasis en Gerencia Estratégica; Ingeniero Comercial; Universidad Técnica de Babahoyo; Babahoyo, Ecuador; wpazmino@utb.edu.ec; (iD https://orcid.org/0000-0002-9996-7910

2. Magister en Administración de Empresas; Diploma Superior en Docencia Universitaria; Economista; Universidad Técnica de Babahoyo; Babahoyo, Ecuador; vmerchan@utb.edu.ec; (D) https://orcid.org/0000-0003-3771-5248

3. Magister en Docencia y Gerencia en Educación Superior; Ingeniero Comercial; Universidad Técnica de Babahoyo; Babahoyo, Ecuador; ejimenez@utb.edu.ec; (D) https://orcid.org/0000-0001-6360-2816

CORRESPONDENCIA

Washington Enrique Pazmiño Gavilánez

wpazmino@utb.edu.ec

Babahoyo, Ecuador

C RECIAMUC; Editorial Saberes del Conocimiento, 2020 


\section{RESUMEN}

La crisis generada por el virus del COVID-19 ha sacudido al mundo poniendo en marcha olas de cambio en cascada con una amplia gama de trayectorias posibles. Si bien es cierto que no se puede predecir el futuro, la planificación estratégica ofrece herramientas para la formulación de políticas exitosas en aras de frenar el impacto ante la crisis de acuerdo a la incertidumbre que se vive. Esto implica explorar y prepararse con una diversidad de estrategias para el futuro que tengan como finalidad identificar nuevas oportunidades y desafíos potenciales y diseñar formas innovadoras de mejorar el bienestar de la población en circunstancias que evolucionan rápidamente como lo ha demostrado durante todo el año, la presencia del virus que de alguna manera ha tomado por sorpresa a todos incrementándose en un abrir y cerrar de ojos. Este documento es un recurso para ayudar a los gobiernos y las organizaciones a utilizar la previsión en la formulación de políticas relacionadas con COVID-19 y el impacto económico y social que este virus ha ocasionado a nivel mundial.

Palabras clave: Pandemia, Planificación, COVID-19.

\section{ABSTRACT}

The crisis sparked by the COVID-19 virus has rocked the world, setting in motion waves of cascading change with a wide range of possible trajectories. Although it is true that the future cannot be predicted, strategic planning offers tools for the formulation of successful policies in order to curb the impact of the crisis according to the uncertainty that exists. This implies exploring and preparing with a diversity of strategies for the future that aim to identify new opportunities and potential challenges and design innovative ways to improve the well-being of the population in rapidly evolving circumstances as demonstrated throughout the year, the presence of the virus that somehow has taken everyone by surprise increasing in the blink of an eye. This document is a resource to help governments and organizations use forecasting in policymaking related to COVID-19 and the global economic and social impact this virus has caused.

Keywords: Pandemic, Planning, COVID-19.

\section{RESUMO}

A crise desencadeada pelo vírus COVID-19 abalou o mundo, colocando em movimento ondas de mudança em cascata com uma ampla gama de trajetórias possíveis. Embora seja verdade que o futuro não pode ser previsto, o planejamento estratégico oferece ferramentas para a formulação de políticas de sucesso a fim de conter o impacto da crise de acordo com a incerteza que existe. Isso implica explorar e se preparar com uma diversidade de estratégias para o futuro que visam identificar novas oportunidades e desafios potenciais e desenhar formas inovadoras para melhorar o bem-estar da população em circunstâncias de rápida evolução, como demonstrado ao longo do ano, a presença do vírus que de alguma forma pegou a todos de surpresa, aumentando em um piscar de olhos. Este documento é um recurso para ajudar governos e organizações a usar previsões na formulação de políticas relacionadas ao COVID-19 e ao impacto econômico e social global que esse vírus causou.

Palavras-chave: Pandemic, Planning, COVID-19. 


\section{Introducción}

Los autores McKee \& Stuckler, (2020) en su estudio expresan, que el "COVID-19 y la pandemia, es ante todo, una crisis sanitaria". Sin embargo, se está convirtiendo rápidamente en una económica también. De acuerdo con Organizacion Mundial del Comercio, (2020) se espera que la producción industrial mundial caiga bruscamente en el primer semestre de 2020 y exista una contracción en la economía de un 2\% para final de año.

Las instituciones públicas de todos los países han adoptado diferentes estrategias. Transformar el distanciamiento social en el encierro, cuarentena, aislamiento, inmunidad al oído, así como también, el empleo de diagnósticos como hisopo nasofaríngeo, temperatura corporal, serología y guantes, uso de desinfectantes, procedimiento de desinfección y muchos otros datos epidemiológicos son parte de las estrategias impuestas para tratar de frenar el impacto ante la crisis producida por el virus. Sin embargo, es interesante la variada tasa de mortalidad mostrada en diferentes regiones. Muchos factores parecen estar implícitos ante la crisis que se presenta, pero no claramente identificado hasta el día de hoy.

El nuevo coronavirus sigue proyectando una larga sombra sobre sociedades, economías y empresas en todo el mundo. Como sociedad, la necesidad de producción de bienes y servicios se incrementa con el paso de la cuarentena, tomando como estrategia la continuidad de los negocios a través del uso de medios digitales que permite mantener el trabajo remoto para lograr el capital inmediato y necesario.

Ahora, a medida que las organizaciones aprenden a manejar la crisis inmediata y los gobiernos comienzan a flexibilizar tentativamente las restricciones, dos consideraciones claves surgen. La primera es operativa: ¿cómo preparar su organización para el regreso a trabajar en esta "nueva norma- lidad"?. Aunque será un desafío difícil, se puede resolver a corto plazo. La segunda es ¿cuáles son las implicaciones a mediano y largo plazo de la crisis? ¿cómo se debe responder estratégicamente? Éstas interrogantes surgen dentro de las discusiones de la sala de juntas y sesiones de planificación en todas las organizaciones considerándose como un escenario de análisis importante.

Este documento está destinado a ayudar a los gobiernos y organizaciones en la aplicación de enfoques de planificación estratégica para fortalecer su trabajo relacionadas con la crisis generada por el COVID-19. En particular, apunta a resaltar las incertidumbres claves y los posibles desarrollos futuros resultantes debido a la pandemia ocasionada por el virus que podrían tener implicaciones para la política tanto a corto como a mediano plazo. Se divide en las siguientes secciones:

1. Incertidumbres y "escenarios" aproximados para la propagación y los efectos en la salud del COVID-19 durante los próximos dos meses a dos años. Estos no son el enfoque del documento, sino un punto de partida necesario para explorar impactos e incertidumbres sistémicos más amplios.

2. Incertidumbres y posibles desarrollos derivados de los impactos del COVID-19 en varios sistemas interconectados: social, tecnológico, económico, medioambiental y de gobernanza, para explorar las implicaciones en varias áreas de políticas públicas.

3. Comprometerse con la incertidumbre: una guía práctica sobre cómo utilizar estos elementos para explorar las implicaciones de las políticas y diseñar recomendaciones para los gobiernos.

\section{Metodología}

Para el desarrollo de este proceso investigativo, se plantea como metodología la en- 
caminada hacia una orientación científica particular que se encuentra determinada por la necesidad de indagar en forma precisa y coherente una situación, en tal sentido Davila, (2015) define la metodología "como aquellos pasos anteriores que son seleccionados por el investigador para lograr resultados favorables que le ayuden a plantear nuevas ideas" (p.66)

- $\mathcal{U}$ Lo citado por el autor, lleva a entender que el desarrollo de la acción investigativa busca simplemente coordinar acciones enmarcadas en una revisión bibliográfica con el fin de complementariedades ideas previas relacionadas a la planificación estrategia ante crisis de COVID 19 a través de una revisión de literatura, para así finalmente elaborar un cuerpo de consideraciones generales que ayuden a ampliar el interés propuesto.

\section{Tipo de Investigación}

Dentro de toda práctica investigativa, se precisan acciones de carácter metodológico mediante las cuales se logra conocer y proyectar los eventos posibles que la determinan. En este sentido, la presente investigación corresponde al tipo documental, definido por Castro (2016), "se ocupa del estudio de problemas planteados a nivel teórico, la información requerida para abordarlos se encuentra básicamente en materiales impresos, audiovisuales y / o electrónicos". (p.41).

En consideración a esta definición, la orientación metodológica incluye la oportunidad de cumplir con una serie de actividades inherentes a la revisión y lectura de diversos documentos, donde se encuentran ideas explicitas relacionadas con los tópicos encargados de identificar una característica inmersa en el estudio. Por lo tanto, se realizaron continuas interpretaciones con el claro propósito de revisar aquellas apreciaciones propuestas por diferentes investigadores en relación al tema de interés, para luego dar la respectiva argumentación a los planteamientos, en función a las necesidades encontradas en la investigación, apoya- dos en las herramientas tecnológicas para la búsqueda de trabajos con valor científico disponibles en la web que tenían conexión con el objetivo principal de la investigación.

\section{Fuentes Documentales}

El análisis correspondiente a las características que predomina en el tema seleccionado, llevan a incluir diferentes fuentes documentales encargadas de darle el respectivo valor científico y en ese sentido cumplir con la valoración de los hechos a fin de generar nuevos criterios que sirven de referencia a otros procesos investigativos. Para Castro,(2016) las fuentes documentales incorporadas en la investigación documental o bibliográfica, "representa la suma de materiales sistemáticos que son revisados en forma rigurosa y profunda para llegar a un análisis del fenómeno" (p.41). Por lo tanto, se procedió a cumplir con la lectura previa determinada para encontrar aquellos aspectos estrechamente vinculados con el tema, con el fin de explicar mediante un desarrollo las respectivas apreciaciones generales de importancia.

\section{Técnicas para la Recolección de la Infor- mación}

La conducción de la investigación para ser realizada en función a las particularidades que determinan a los estudios documentales, tiene como fin el desarrollo de un conjunto de acciones encargadas de llevar a la selección de técnicas estrechamente vinculadas con las características del estudio. Bolívar, (2015), refiere, que es "una técnica particular para aportar ayuda a los procedimientos de selección de las ideas primarias y secundarias". (p.71).

Tal como lo expresa, Bolívar, (2015) "Las técnicas documentales proporcionan las herramientas esenciales y determinantes para responder a los objetivos formulados y llegar a resultados efectivos" (p. 58). Es decir, para responder con eficiencia a las necesidades investigativas, se introdujeron como técnica de recolección el método in- 
ductivo, que hizo posible llevar a cabo una valoración de los hechos de forma particular para llegar a la explicación desde una visión general. El autor Bolívar, (2015) tambien expresa que las técnicas de procesamiento de datos en los estudios documentales "son las encargadas de ofrecer al investigador la visión o pasos que deben cumplir durante su ejercicio, cada una de ellas debe estar en correspondencia con el nivel a emplear" (p. 123). Esto indica, que para llevar a cabo el procesamiento de los datos obtenidos una vez aplicadas las técnicas seleccionadas, tales como: fichas de resumen, textual, registros descriptivos entre otros, los mismos se deben ajustar al nivel que ha sido seleccionado.

\section{Resultados}

La pandemia generada por el COVID-19 está creando una alta incertidumbre que afecta todas las áreas y que se viene evidenciando desde que se declara alarma mundial el 11 de marzo del 2020 hasta la actualidad. Más allá de las preguntas sobre la propagación futura y los impactos de la enfermedad en la salud pública, existe una interrogante significativa con respecto a los efectos que pueden surgir de la enfermedad, las respuestas a ella, y cómo estos interactuarán en múltiples sistemas interconectados durante los próximos años. Este contexto de mayor turbulencia acentúa los desafíos existentes y aumenta el riesgo de que los gobiernos tomen decisiones políticas basadas en suposiciones demasiado apresuradas o estrechas sobre el futuro.

La planificación estratégica es un enfoque para ayudar a la toma de decisiones frente a la incertidumbre. Se basa en la planificación de políticas públicas y privadas responsables y eficaces en aras de prepararse ante una amplia gama de posibles desarrollos futuros y sus implicaciones

\section{Incertidumbres sobre la propagación y los efectos sobre la salud del COVID-19}

El desacuerdo y la incertidumbre persisten dentro de la comunidad de investigación médica y epidemiológica sobre una gran cantidad de aspectos clave de COVID-19 y sus impactos. Hasta que se logre una base de evidencia confiable y un consenso sobre estos puntos es prudente que los responsables de la formulación de políticas mantengan todos los resultados plausibles en juego en su toma de decisiones incluidos aquellos, que pueden parecer improbables o extremos (Luisetto, Rafa, Edbey, \& Mashori, 2020). Estas incertidumbres incluyen:

- La velocidad a la que se propagará la enfermedad en diferentes áreas y bajo diferentes medidas de mitigación.

- La tasa de letalidad por infección en condiciones ideales y la tasa de letalidad efectiva en ausencia de atención médica adecuada (como puede ser el caso en varios países o regiones).

- La prevalencia de casos leves no notificados hasta ahora entre la población.

- Los impactos a largo plazo sobre la salud de las poblaciones infectadas.

- El alcance y la duración de la inmunidad adquirida entre las poblaciones infectadas.

- El momento, la disponibilidad y la confiabilidad de las pruebas generalizadas.

- El momento, la disponibilidad y la eficacia de posibles tratamientos o vacunas.

Con base en estas incertidumbres, se puede derivar una variedad de escenarios ilustrativos para facilitar la comprensión y la discusión que ofrecen una representación aproximada de la posible amplitud de trayectorias para la futura propagación e impacto de COVID-19 en los próximos años, resumidos en tres categorías amplias basadas en el aumento de la gravedad de "malo" a "peor" e "incluso peor aún", proporcionan un punto de partida para ayudar a los analistas de políticas públicas y los responsables de la toma de decisiones a explorar los

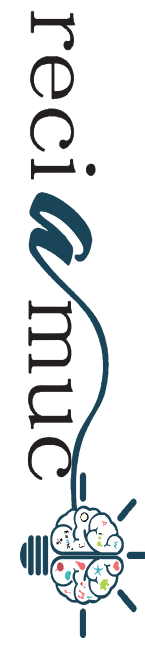


posibles impactos e interacciones adicionales de COVID-19 en varios sistemas y áreas de política relacionadas (Zhaoa, 2020).

Tabla 1. Escenarios ilustrativos de propagación y efectos futuros del COVID-19

\begin{tabular}{|c|c|c|c|}
\hline Período & "Malo" & "Peor" & "Peor aún" \\
\hline $\begin{array}{l}\text { Junio agosto } \\
2020\end{array}$ & $\begin{array}{l}\text { Pico de casos y muertes } \\
\text { rápidamente y declinar }\end{array}$ & $\begin{array}{l}\text { Casos estables donde } \\
\text { mitigación mantenida, } \\
\text { subir en otro lugar }\end{array}$ & $\begin{array}{l}\text { Las medidas de mitigación se } \\
\text { rompen } \\
\text { abajo } \\
\text { Aumento rápido de casos y } \\
\text { fallecidos }\end{array}$ \\
\hline $\begin{array}{l}\text { septiembre } \\
2020 \text { - junio }\end{array}$ & Inmunidad generalizada & $\begin{array}{l}\text { En curso moderado } \\
\text { aún se requiere } \\
\text { mitigación }\end{array}$ & $\begin{array}{l}\text { Desastre humanitario como } \\
\text { la enfermedad abruma }\end{array}$ \\
\hline 2021 & $\begin{array}{l}\text { Centrarse en las pruebas } \\
\text { Cambiar el apoyo a áreas / países } \\
\text { más necesitado }\end{array}$ & para todos menos inmunes & países en desarrollo \\
\hline Julio 2021 - & $\begin{array}{l}\text { Efectivo universal } \\
\text { vacunación } \\
\text { Fin de la crisis del COVID-19 } \\
\text { Centrarse en la reconstrucción } \\
\text { de la economía } \\
\text { y prepararse para el futuro } \\
\text { crisis / cambios }\end{array}$ & $\begin{array}{l}\text { Parcialmente eficaz } \\
\text { vacunación } \\
\text { "Gripe 1-3x" en curso } \\
\text { Nuevo modelo económico } \\
\text { basado en la necesidad de } \\
\text { caja fuerte } \\
\text { distanciamiento }\end{array}$ & $\begin{array}{l}\text { Sin vacunación eficaz } \\
\text { "Gripe } 5-10 \text { veces mayor" en } \\
\text { curso } \\
\text { Agitación económica y social }\end{array}$ \\
\hline
\end{tabular}

Fuente: (King, 2020)

\section{Incertidumbres y posibles desarrollos sobre los impactos del COVID-19 en va- rios sistemas interconectados.}

La siguiente es una lista inicial de incertidumbres y posibles desarrollos que podrían surgir a medida que COVID-19 impacta e interactúa con diferentes sistemas humanos y naturales. Cada incertidumbre va seguida de dos o más desarrollos posibles. Estos desarrollos representan extremos contrastantes en un amplio espectro de posibles trayectorias y resultados. Si bien, la realidad será ciertamente más matizada y compleja, el propósito es provocar que el lector mire más allá de sus suposiciones y expectati- vas actuales sobre el futuro y que considere conscientemente y se prepare para una variedad de condiciones alternativas (Olombi, Petrini, \& Maffi, 2020).

\section{Sociedad}

¿Desencadenará la crisis un cambio en las actitudes de la sociedad hacia la cooperación en bienes públicos, o dominará el interés propio?

Cooperación: al salir del trauma, la humanidad desarrolla una mayor propensión a la cooperación respondedor a la constatación de que una cadena es tan fuerte como su eslabón más débil. Las comunidades se unen para proteger a los vulnerables y de- 
fender sus intereses comunes tanto a nivel local como global. El apoyo ciudadano a la solidaridad y la cooperación se extiende a una serie de cuestiones para las que una acción eficaz a nivel mundial podría evitar consecuencias negativas desproporcionadas para la humanidad (por ejemplo, el cambio climático, la persistente, la resistencia a los antimicrobianos y las amenazas planteadas por los desarrollos tecnológicos emergentes). (Olombi, Petrini, \& Maffi, 2020)

Interés propio: el miedo, la desconfianza y el comportamiento egoísta insinuaron, tanto dentro como entre sociedades. La acción unilateral (por ejemplo, para asegurar los recursos médicos) y la tendencia a culpar a otros siembran división y desunión y enmarcan la lucha global contra las enfermedades pandémicas y otras crisis como un juego de suma cero. La tragedia de los comunes empeora. (Olombi, Petrini, \& Maffi, 2020)

Alianzas frenéticas: las crisis alimentan sucesivas oleadas de solidaridad, con la atención de la sociedad cambiando rápidamente de un tema a otro. Se forman alianzas y en ocasiones improbables entre grupos con intereses temáticos comunes, pero siguen siendo fluidas y, a menudo, superficiales. Por lo tanto, la sociedad está socialmente comprometida, pero lucha por adaptarse al rápido ritmo de cambio y al alto nivel de complejidad conduciendo a una sobrecarga de información y fatiga por crisis, limitando los esfuerzos sostenidos hacia un cambio positivo duradero. (Olombi, Petrini, \& Maffi, 2020).

\section{¿El curso de la urbanización evolucionará hacia la desurbanización o la reurbanización?}

Desurbanización: una parte significativa de los habitantes urbanos se traslada a áreas rurales y suburbanas El teletrabajo generalizado libera a muchos de la necesidad de desplazarse normalmente para trabajar. Con los riesgos continuos de infección por COVID-19 o nuevas enfermedades, la concentración de la población se considera una desventaja en el lugar de un beneficio de la vida urbana, mientras que las ciudades más pequeñas ofrecen menos vigilancia, una vida más ecológica y espaciosa, una mayor oportunidad para la propiedad de la propiedad y el potencial para estilos de vida más autosuficientes.

Reurbanización: la aglomeración urbana continúa y las ciudades salen como "ganadoras" debido a concentración de infraestructura (médica y de conocimientos). La reutilización del espacio comercial y de oficinas para un uso mixto y un alojamiento y ocio residencial más asequible y espacioso ayuda a abordar las limitaciones anteriores en la calidad de vida urbana. Los espacios de coworking localizados y los corredores para peatones y ciclistas mejorados ayudan a reducir la contaminación del aire. La infraestructura sin contacto está integrada con el aparato de vigilancia necesario para permitir una mezcla segura de la población.

Enclaves: el contraste entre lo urbano y lo rural se vuelve menos significativo a medida que las personas se mueven hacia estilos de vida de enclave autónomos. La movilidad entre enclaves es limitada y la infraestructura no utilizada se reutiliza en mega complejos de uso mixto. Las personas mantienen contacto en persona con los miembros de su enclave y dependencia de la tecnología para interactuar con el resto del mundo. Sin embargo, el descontento se agrava por la pérdida de libertad de movimiento y la separación física agudiza la desigualdad. (Ozili \& Thankom, 2020)

¿Cuál será el nivel de fracturación social y en qué líneas de falla?

De acuerdo a lo descrito por los autores es Ozili \& Thankom, (2020) se tiene:

Creciente desigualdad: desigualdades magnificadas por la crisis (por ejemplo, ingresos, raciales, generacionales, digitales alfabetización) crean un resentimiento profundo y duradero y una creciente protesta social. 
Guerra cultural: la sociedad se fragmenta de nuevas formas a lo largo de las líneas populistas existentes, como obligación de proteger a los más vulnerables, o medidas para restringir el movimiento de personas consideradas una amenaza para la salud de la comunidad.

Encontrar la solidaridad: la experiencia de la acción colectiva durante la crisis impulsa nuevas formas de solidaridad, incluido el respaldo para una compensación más alta para los trabajadores esenciales con salarios más bajos, y apoyo para los miembros de la sociedad afectados de manera desproporcionada. Las tensiones inter generacionales se alivian a medida que las poblaciones mayores aceptan un nuevo contrato social que brinda mayores oportunidades para los jóvenes. Los jóvenes desarrollan una nueva apreciación por los mayores y una mayor sensibilidad a sus necesidades y vulnerabilidades.

Clasismo COVID: la sociedad se divide en niveles en función del riesgo que se percibe que las personas presentan a la sociedad, afectando su capacidad para volver al trabajo y acceder a determinados espacios públicos. Estos niveles podrían basarse en las clasificaciones de "inmunidad" de COVID-19 por prueba o estado de vacunación, y en si las personas adoptan medidas de control de propagación, como el uso de aplicaciones de seguimiento y localización.

\section{¿Será COVID-19 un revés o un acelerador para la igualdad de género?}

Contratiempo: los ingresos y el potencial profesional de las mujeres se reducen debido a las presiones de la atención domiciliaria durante oleadas de confinamiento que limitan desproporcionadamente su capacidad para trabajar. La pérdida de empleos persiste en las industrias informales y con salarios más bajos, donde en algunos países las mujeres están más concentradas. La salud materna se ve comprometida como resultado de desbordamientos en los sistemas de salud y millones que pierden el acceso a los servicios de planificación familiar.

Acelerador: un mayor reconocimiento del valor del trabajo en persona "esencial" conduce a mejores compensación y condiciones de trabajo por ocupaciones desempeñadas de manera desproporcionada por mujeres.

La expansión masiva del teletrabajo permite horarios de trabajo más flexibles y favorables a la familia que benefician a ambos sexos. La expansión de la renta básica universal permite una compensación económica tanto para las mujeres como para los hombres que proporcionan cuidados domésticos y otros trabajos sociales beneficiosos pero que antes no eran remunerados. Esto está respaldado por el reconocimiento del liderazgo femenino efectivo durante la crisis (Ozili \& Thankom, 2020).

\section{¿EI COVID-19 hará que las presiones migratorias crezcan, disminuyan o cambien?}

Crecen las presiones migratorias: COVID-19 provoca severos aspectos económicos, sociales y de gobernanza rupturas y conflictos civiles en varios países, que conducen a movimientos masivos de refugiados y migrantes económicos. Mientras tanto, la automatización acelerada y el aumento del desempleo debido a COVID-19 conducen a una menor demanda de inmigrantes en los países receptores tradicionales. Los brotes concentrados de COVID-19 entre las comunidades de migrantes y / o como resultado del movimiento de la población refuerzan la resistencia a los flujos de migrantes.

Las presiones migratorias se alivian: las tecnologías de rastreo implementadas para COVID-19 sirven como plataforma para un análisis generalizado de datos de posibles migrantes, lo que permite una mayor selectividad y una gestión eficaz de la migración y aumenta el apoyo público para un aumento de los flujos. Existe una mayor conciencia de la necesidad de que los migrantes satis- 
fagan las necesidades laborales en muchos trabajos "esenciales" en la salud, la atención domiciliaria y la agricultura. En otras ocupaciones, la adopción acelerada del teletrabajo reduce la necesidad de migración física para acceder al empleo y / o permite el asentamiento en áreas despobladas.

Cambios migratorios: el riesgo continuo de infección limita los viajes a corto plazo y migración a asentamiento a más largo plazo (después de los períodos de cuarentena necesarios). Las zonas libres de COVID con economías revividas se utilizan en imanes para los mejores talentos mundiales. (King, 2020)

¿EI COVID-19 acelerará la reducción del espacio cívico o catalizará una revitalización de las organizaciones de la sociedad civil y su papel?

Reducción del espacio cívico: COVID-19 debilita aún más la capacidad y la influencia de la sociedad civil, ya que; la toma de decisiones de emergencia por parte de los gobiernos reduce el tiempo para la consulta, una mentalidad de crisis justifica las limitaciones a la disidencia y las presiones financieras conducen una reducción de la financiación de los gobiernos y el público. La movilización y el activismo cívicos están limitados por las restricciones a las reuniones en persona, así como por el aumento de la vigilancia y la censura en la esfera digital.

Renacimiento cívico: organizaciones de la sociedad civil nuevas y existentes, empresas con fines sociales y los movimientos ciudadanos habilitados digitalmente ganan apoyo y legitimidad como resultado de sus contribuciones a la defensa del interés público durante la crisis del COVID-19. Asumen un papel clave en la convocatoria del diálogo democrático, articulando visiones positivas para el cambio, haciendo que los gobiernos rindan cuentas y entre soluciones innovadoras, convirtiéndose en actores cruciales en un enfoque de múltiples partes interesadas más diverso para lograr la colaboración en temas globales. (King, 2020)

\section{Tecnología}

¿Llevará la crisis al triunfo o la desilusión de la ciencia y la tecnología médica?

De acuerdo a lo descrito por los autores es Ozili \& Thankom, (2020) se tiene:

Triunfo: Aumento de la investigación e innovación científicas y médicas colaborativas, incluso en la investigación genómica, la virología y el uso de IA en el diagnóstico y el desarrollo de vacunas conducen a avances inesperados con dividendos sociales más amplios.

Desilusión: la confianza y la confianza en la ciencia disminuyen debido a mensajes contradictorios e inconsistentes sobre hechos relacionados con la enfermedad, especialmente en el caso de una interrupción inesperada, como un tratamiento recomendado incorrecto o la imposibilidad de producir una vacuna eficaz.

¿La interacción digital se convertirá en un pilar de la vida social?

Renacimiento de la realidad virtual: el mercado de plataformas de interacción digital sigue creciendo y tecnologías como el turismo de realidad virtual se expanden a medida que mantiene la renuencia de las personas a salir de casa, incluidas nuevas opciones de socialización basadas en la realidad virtual, especialmente entre los jóvenes.

Latigazo cervical digital: El período de intensa separación física de los demás conduce a una oposición reacción donde las personas se enfocan en crear más y nuevos espacios para la conexión (higiénica) en persona. Las plataformas de interacción digital vuelven a niveles (casi) anteriores a la crisis.

¿EI COVID-19 conducirá a una era posterior a la privacidad o una reacción a favor de la privacidad?

Post-privacidad: el equilibrio entre COVID-19 y la economía está habilitado por la adopción masiva de tecnologías de vigi-

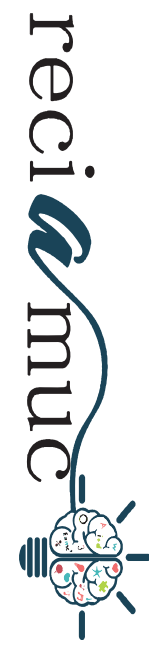


lancia personal. Estos evolucionan más allá del rastreo de contactos para incluir el monitoreo en tiempo real de las respuestas fisiológicas. Aunque inicialmente voluntarias, estas tecnologías se vuelven obligatorias de hecho debido al acceso que permiten al empleo, los espacios públicos y las reuniones sociales. A medida que COVID-19 retrocede, estas tecnologías se mantienen en su lugar debido a sus beneficios más amplios para la salud y la seguridad, incluida la protección contra amenazas potenciales como el bioterrorismo.

A favor de la privacidad: la presión repentina para la vigilancia masiva centra la atención pública en el tema de privacidad digital. La fuerte presión pública conduce al desarrollo de nuevas tecnologías e instituciones diseñadas para salvaguardar la privacidad mientras se aprovechan los datos de población para el bien público. (King, 2020)

\section{Economía}

Lo descrito por los autores es Ozili \& Thankom, (2020) lleva a la formulacion de la siguiente pregunta:

¿Se reformulará el eterno debate entre el estado y el mercado y dará lugar a que los estados asuman un papel más importante en la economía del futuro, o el sector privado liderará la recuperación?

Nuevo estatismo: los gobiernos, que han apoyado no solo a una minoría vulnerable sino a grandes mayorías de sus poblaciones, adquieran nueva legitimidad y mandatos para actuar en la economía. Esto conduce a estados de bienestar renovados y expandidos, que se extienden a gobiernos que retienen el control de grandes sectores de la economía anteriormente ocupados por el sector privado. La política industrial se vuelve más importante.

Resurgimiento del sector privado: muy endeudado por sus acciones para mantener viva la economía apoyo, los gobiernos recurren al sector privado para ofrecer el dinamismo necesario para reiniciar la economía.
¿Dónde está el empleo y el desempleo?

Empleos para los jóvenes: La recuperación del mercado laboral favorece a los jóvenes, en esa innovación digital crea nuevos puestos de trabajo basados en conjuntos de habilidades mejor desarrollados en las generaciones más jóvenes conocedoras de la tecnología. Los trabajadores más jóvenes están en mejores condiciones de asumir el riesgo de un mercado laboral más flexible.

Empleos para los mayores: La recuperación del mercado laboral favorece a las personas mayores, que tienen más experiencia. Las personas mayores vuelven a ingresar al mercado o retrasan la jubilación debido a los impactos económicos de la crisis (por ejemplo, en los ahorros para la jubilación), lo que desplaza a los más jóvenes de los trabajos nuevos y anteriores.

Empleos para lo esencial: el mercado laboral recompensa a aquellos (en todos los niveles de habilidad) cuyo trabajo esEs esencial, pero no se puede automatizar fácilmente ni realizar de forma remota, y los salarios y los beneficios aumentan para compensar los riesgos adicionales del contacto físico en un mundo que todavía está amenazado por la infección.

Empleos para nómadas digitales: a medida que la competencia global reduce los ingresos de los teletrabajadores, el empleo crece para aquellos que viven o están dispuestos a trasladarse a comunidades con alta conectividad digital y menor costo de vida.

Empleos para robots: el mercado laboral nunca se recupera por completo debido a una serie de factores en conflicto, por ejemplo, los seres humanos son vistos como un factor de riesgo en la economía. Las industrias aceleran la automatización para volverse más resistentes y eficientes. La transición se ve facilitada por la continuación de las políticas de apoyo a los ingresos implementadas durante la crisis. (Ozili \& Thankom, 2020) 


\section{¿EI COVID-19 acelerará o revertirá la tendencia hacia la concentración empresarial?}

Concentración empresarial: la crisis del COVID-19 empuja a todas las empresas, excepto a las más grandes, a bancarrota. Las empresas líderes (especialmente las que están posicionadas para beneficiarse más de la transformación digital acelerada) hacen un barrido para adquirir competidores debilitados. Las grandes empresas con presencia global consolidan su posición a través del auge del comercio electrónico y su capacidad logística para atender mercados distantes en un momento de necesidad. La política industrial continental se centra en ayudar a los titanes locales a competir a escala mundial.

Descentralización digital: la crisis actúa como una ola de disrupción que arrasa con millones de empresas "zombis" improductivas, mientras que obligan a muchas otras a adoptar tecnologías digitales que mejoran la productividad para sobrevivir. Esta turbulencia crea una multitud de nuevos nichos, incluso para empresas más pequeñas y ágiles con estructuras de bajo costo y / o lealtad del consumidor local. Un movimiento liderado por ciudadanos para garantizar un campo de juego nivelado de plataformas digitales abiertas y neutrales permite una economía global en red altamente innovadora y competitiva de pequeñas empresas interconectadas mediadas por blockchain e IA. Las reglas de esta economía digital fluida son tales que el tamaño de una empresa grande ya no es una ventaja competitiva significativa. (King, 2020)

\section{¿Se reglobalizará o reubicará la economía?}

Reglobalización: la crisis del COVID-19 cataliza nuevos vínculos comerciales e inversiones globales parapara hacer frente a los shocks de oferta localizados. La digitalización acelerada permite una nueva ola de globalización que es más transparente y eficiente, por ejemplo, reduce significativamente la fricción en los cruces fronterizos.
Localización física combinada con globalización digital: la crisis pone de relieve las vulnerabilidad es de las cadenas de valor globales, lo que lleva a la diversificación de la fabricación, la agricultura y la extracción de recursos naturales hacia productores más locales (nacionales o continentales) e iniciativas de economía circular destinadas a una reutilización más eficiente de los recursos físicos dentro de cada región. Al mismo tiempo, el trabajo, las ideas, los diseños, los datos y el software circulan cada vez más libremente como parte de una economía digital global, eludiendo continuamente las barreras a los flujos de información.

Bloques regionales: la crisis acentúa las divisiones y la desconfianza entre Estados Unidos y China mientras obligando a los gobiernos europeos y de otros países a elegir un bando o seguir su propio camino. La incapacidad de separar los datos sensibles de los no sensibles da como resultado un endurecimiento de las fronteras digitales entre regiones digitales cada vez más paralelas e incompatibles. El hardware paralelo (5G), el software y los servicios digitales evolucionan hacia sistemas de logística paralelos en los que incluso el comercio físico y los viajes entre bloques regionales se vuelven restringidos.

Autarquía: Los riesgos continuos de infección llevan a muchos países y localidades a aislarse de la economía global, fomentando la autosuficiencia local (asistida por producción automatizada y energía renovable) y caracterizada por fuertes movimientos de "compra local" y "vacaciones en casa" (Gautret, Lagier, Parola, Hoang, \& VT., 2020).

\section{Ambiente}

¿Habrá un movimiento hacia o desde la sostenibilidad ambiental?

Hacia: La crisis del COVID-19 trae el vínculo entre la sostenibilidad ambiental y la resiliencia a un primer plano, lo que lleva a las sociedades a buscar un mayor equilibrio

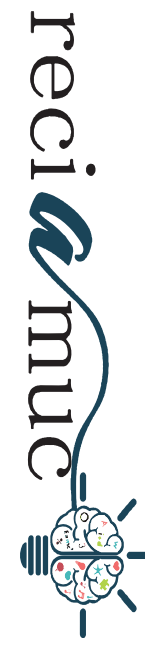


en las prioridades ambientales, económicas y sociales. Demuestra cómo retrasar la acción preventiva necesaria puede resultar en costos mucho mayores, lo que lleva a un apoyo público generalizado para una acción social sólida para abordar las crisis climáticas y ambientales antes de que puedan empeorar.

Lejos: el medio ambiente es visto como secundario o en oposición a la recuperación económica por parte de gobiernos y hogares, algunos de los cuales se encuentran en graves dificultades económicas. Las medidas ambientales se relajan o posponen, y la degradación ambiental continúa o se acelera para compensar la actividad económica perdida, por ejemplo a través de mayores emisiones.

Enfoque de salud: la crisis centra una mayor atención en la salud y en las conexiones entremedio ambiente y salud. Hay un cambio en los recursos para priorizar aquellos problemas ambientales que se perciben como los que tienen las consecuencias más directas para la salud.

Vigilancia ambiental: la gravedad de la crisis del COVID-19 conduce a un impulso para y enfoques punitivos a los problemas ambientales. Comenzando con un enfoque en los mercados húmedos y el comercio de vida silvestre, esto se expande para restringir la producción industrial de carne, la contaminación del aire urbano y otros factores ambientales asociados con amenazas potenciales para la salud humana (Ogen, 2020).

¿Habrá un retorno a la tendencia anteriormente creciente en las prácticas comerciales sostenibles y socialmente responsables, o las prioridades de supervivencia superarán esas preocupaciones?

Responsabilidad: Bajo la presión de inversores, reguladores, accionistas y / o consumidores, La conducta empresarial responsable se arraiga más profundamente en la cultura y las instituciones corporativas (por ejemplo, a través de estándares de inver- sión ambientales, sociales y de gobierno (ESG) o la adopción de estructuras comerciales pro-sociales como las corporaciones y cooperativas de beneficio). La administración ambiental se incorpora aún más como una estrategia de resiliencia para garantizar la viabilidad comercial frente a interrupciones de la cadena de suministro, amenazas ambientales y otras posibles perturbaciones.(Ogen, 2020).

Supervivencia: las empresas ven cualquier otra cosa que no sean las estrategias de supervivencia a corto plazo y centradas en los resultados como una prioridad baja dado el inmenso impacto económico. Una profunda recesión económica frena cualquier apetito entre inversores, consumidores o gobiernos para impulsar una agenda de sostenibilidad.

Ola de desperdicio: la conciencia de la higiene entre los consumidores lleva a las empresas a prácticas de mayor desperdicio, como mayores volúmenes de envases y más productos de un solo uso.

\section{¿Hasta qué punto los consumidores cambiarán sus prioridades?}

Una revolución posterior a las cosas: la crisis del COVID-19 rompe los patrones de consumo, lo que lleva a una depresión prolongada en la demanda a medida que las personas priorizan la construcción o reconstrucción de ahorros. La mayoría de los consumidores se dan cuenta de que pueden prosperar con menos bienes materiales, por lo que los patrones de consumo cambian aún más hacia los bienes digitales y experimentales, ya que los viajes siguen siendo limitados debido a problemas de salud.

Una revolución de cosas por correo: la crisis provoca una re-materialización masiva en la que los consumidores utilizan el comercio electrónico para equipar sus espacios de vida para una mayor comodidad, teletrabajo continuo y posibles períodos futuros de confinamiento (por ejemplo, equipos de ofi- 
cina y ejercicio, electrodomésticos y muebles, actualizaciones de entretenimiento digital). Aumenta la demanda de bicicletas, scooters y automóviles para reemplazar los viajes compartidos y el transporte público que se considera inseguro.(Ogen, 2020).

\section{Gobernanza, geopolítica y desarrollo in- ternacional}

¿Cuáles podrían ser los impactos para la gobernabilidad y la democracia?

Aumento del autoritarismo: el deseo de una respuesta estatal fuerte junto con la falta de la capacidad se traduce en autoritarismo y políticas de hombres fuertes en algunos estados, además de posibilitadas por una mayor capacidad de vigilancia digital a nivel mundial.

Reacción contra el gobierno: las poblaciones culpan a los gobiernos / élites por el confinamiento restrictivo medidas, la recesión económica causada por la pandemia, o ambos. A medida que las condiciones empeoran, aumenta el apoyo a los mensajes populistas que buscan echar la culpa a otros.

Gobernanza basada en evidencias: mayor reconocimiento de la importancia de las estadísticas, la investigación y la política basada en pruebas refuerza el apoyo a una gobernanza más tecnocrática. Los electorados recompensan a los gobiernos que se considera que gestionan de forma competente tanto la crisis sanitaria como sus consecuencias económicas.

Democracia deliberativa o participativa: La crisis del COVID-19 acelera la proliferación y adopción de herramientas de ciudadanía digital, fortaleciendo la democracia conectando gobiernos y ciudadanos y permitiendo el desarrollo de enfoques más deliberativos o participativos (Ogen, 2020).

¿Cómo podría el COVID-19 afectar la dinámica política regional (por ejemplo, urbana o rural) $y$ los cambios de poder?
Centros urbanos: la aglomeración continúa y las grandes ciudades salen de la crisis como "Ganadores" debido a la concentración de la infraestructura (médica) y la generación y difusión de conocimientos. Esto conduce a una continuación / aceleración de la manifestación de las ciudades como centros primarios de poder político.

Centros rurales: las áreas rurales obtienen factores de atracción adicionales como ciudades y áreas densamente pobladas se perciben cada vez más como "incubadoras" de brotes potencialmente más frecuentes. Esto conduce a un posible cambio en las actitudes políticas y los bloques de votación y / o impulsa una mayor autonomía. (Ogen, 2020).

Polinización cruzada: traumas compartidos de la crisis del COVID-19 y sus impactos posteriores combinados con una moderada tendencia a la desurbanización crean una nueva base para la identidad común y cambian la trayectoria de las crecientes divisiones políticas entre las áreas rurales y urbanas. Si bien todavía existen islas ideológicas, existe un sentido de identidad nacional colectiva y valores compartidos que se extiende hacia un mayor centrismo.

El resentimiento rural: si bien existen puntos críticos, las comunidades rurales se libran en gran medida de lo peor de la aumento de la pandemia y el resentimiento por las consecuencias económicas sufridas por las comunidades rurales por el bien de los habitantes urbanos más vulnerables. La polarización crece y los oportunistas políticos alimentan aún más las Ilamas. (Ogen, 2020). ¿Cómo podría afectar COVID-19 a los Objetivos de Desarrollo Sostenible (ODS) globales?

Respuesta de emergencia: Los ODS a más largo plazo pierden su relevancia frente a importantes catástrofes humanitarias que revierten gravemente los avances logrados con tanto esfuerzo en el desarrollo mundial. Esta tendencia se intensifica ante la ausencia de un mundo 'post-COVID' y / o sucesi- 
vas oleadas de brotes.

El mundo en desarrollo entra en un período más tumultuoso de perturbaciones repetidas a gran escala (por ejemplo, el flagelo de las langostas que actualmente amenaza la seguridad alimentaria en África Oriental).

Perspectiva sistémica ganada: La visión holística del desarrollo de los ODS se refuerza a medida que es una nueva apreciación de la interconexión e interdependencia de los resultados del desarrollo humano y la seguridad humana. Los recursos limitados requieren priorización entre objetivos, pero también estimulan la innovación y la colaboración en el sector del desarrollo.

Enfoque en salud: enfoque intenso en reunir recursos para fortalecer los sistemas de salud a nivel mundial, particularmente en la difusión de la vacuna COVID-19, conducen a avances en la salud, pero tienen el costo de una perspectiva de resiliencia más sistémica en el desarrollo. (Ozili \& Thankom, 2020)

\section{¿Cómo podría COVID-19 alterar los patrones de} cooperación internacional para el desarrollo?

Cooperación mundial: la emergencia sanitaria mundial y las consecuencias económicas desencadenan un nuevo compromiso con la cooperación para el desarrollo que va más allá del enfoque tradicional Norte-Sur para centrarse en el aprendizaje mutuo y la solidaridad multidireccionales. La inversión pública global se convierte en el nuevo enfoque para resolver los desafíos del desarrollo. Esto implica financiación pública internacional en condiciones concesionarias para promover el desarrollo sostenible e incluye la AOD, así como la cooperación triangular y Sur-Sur. (Ozili \& Thankom, 2020)

Cooperación Sur-Sur: Debido a la falta de coherencia y solidaridad en la respuesta global aCOVID-19, los países en desarrollo salen de la crisis con niveles más bajos de confianza, lo que lleva a cambios a largo plazo lejos de la cooperación al desarrollo con el Norte Global y / o al fortalecimiento de asociaciones entre países de ingresos medianos y bajos y organizaciones multilaterales e instituciones.

Cooperación Norte-Sur: COVID-19 conduce a graves crisis humanitarias y de seguridad alimentaria que impactan a los países vecinos de manera diferente dados los diferentes niveles de vulnerabilidad y dinámicas de poder dentro de las subregiones del Sur Global. El resultado es un aumento de la desigualdad regional entre países y la tensión por la afluencia de refugiados que contribuye a la desintegración regional, Io que a su vez refuerza la importancia relativa de la cooperación Norte-Sur y la AOD.

\section{Comprometerse con la incertidumbre: una guía práctica}

Las incertidumbres y los posibles desarrollos descritos en la sección anterior son solo algunos entre muchos otros que podrían identificarse y considerarse. Se presentan como un punto de partida práctico para aplicar la prospectiva a la formulación de políticas relacionadas con COVID-19 y sus secuelas

\section{Previsión de mejores políticas: nuevos pasos}

Se recomienda que los gobiernos y las organizaciones adopten un enfoque concertado y sistemático para incorporar la previsión en la formulación de políticas durante la crisis de COVID-19 y más allá (King, 2020). Esto involucra:

Trabajar con profesionales experimentados en prospectiva estratégica para diseñar y facilitar procesos de prospectiva en apoyo de las prioridades políticas clave. Estos van desde una breve serie de talleres de prospectiva "sprint" hasta ejercicios más largos que involucran exploración de horizontes, planificación y visión de escenarios, y la participación de una amplia gama de participantes y perspectivas.

Integrar la prospectiva estratégica a las estructuras y procesos en curso de formula- 
ción de políticas.

Colaborar entre gobiernos y otras organizaciones para aunar esfuerzos en la exploración de incertidumbres futuras y sus implicaciones en áreas clave de interés compartido.

Dichos esfuerzos apoyan la formulación de políticas públicas más responsables, innovadoras y con visión de futuro, tanto para la crisis de COVID-19 como en el contexto más amplio en curso de alta incertidumbre y cambios rápidos.

\section{Conclusiones}

La estrategia es una consideración fundamental para la gestión de crisis, proporciona una hoja de ruta clara que marca el rumbo, establece prioridades y define las acciones necesarias, así como también, las consideraciones posteriores a la recuperación de COVID-19. Si bien no podemos predecir con exactitud el resultado final de COVID-19, mantener un pulso en su evolución en los respectivos destinos y medir el impacto en los objetivos públicos es esencial para adaptarse y responder rápidamente.

La pandemia de COVID-19 disminuirá con el tiempo y la gente comenzará a retomar su vida con una nueva normalidad marcada por lo vivido durante todo el tiempo en cuarentena, lo aprendido y lo aceptado demostrándonos que la vida es tan vulnerable y que este tipo de escenarios vienen a romper paradigmas y sociedades en todos los aspectos.

Para maximizar los ingresos antes y después del repunte de la demanda mundial de los distintos sectores productivos, éstos y sus gobiernos necesitan comprometerse continuamente con sus clientes actuales y potenciales, ser de apoyo y seguimiento de los planes de acción de recuperación. Estos planes de acción deben estar respaldados por un seguimiento, evaluación y aprendizaje en el marco de presupuestos financieros sólidos. El financiamiento para la implementación de planes de acción dependerá en gran medida, de los recursos financieros proporcionados por los gobiernos, así como los presupuestos existentes de los organismos de ejecución.

Sin embargo se puede evidenciar que durante el tiempo en pandemia las organizaciones han modificado sus patrones y de manera individualizada han buscado reajustarse con sus propias estrategias para seguir adelante con las herramientas existentes como lo son el teletrabajo, las reuniones con distanciamiento social, entre otras, tomando las medidas de bioseguridad necesarias al fin de abordar y continuar de alguna manera con las exigencias globales.

\section{Recomendaciones}

En el contexto de COVID-19, la prospectiva contribuye a una mejor formulación de políticas de las siguientes maneras:

Consejos y recomendaciones de políticas de pruebas de resistencia y pruebas futuras. Las estrategias basadas en suposiciones estrechas sobre el futuro pueden resultar ineficaces o contraproducentes si cambian las condiciones imperantes. Por ejemplo, puede ser peligroso basar las políticas en el supuesto de que las medidas de confinamiento se pueden poner fin de manera segura en unos pocos meses, o que la opinión pública sobre temas clave (por ejemplo, medio ambiente, desigualdad, vigilancia) permanecerá constante. Preguntar qué tan bien se desempeñarían las políticas actuales o propuestas en diferentes condiciones futuras puede ayudar a que estas políticas sean más sólidas y adaptables.

Identificar nuevos desafíos y oportunidades. Considerar con anticipación posibles desarrollos futuros permitir comenzar antes a trabajar en estrategias para prevenir o mitigar nuevos desafíos o aprovechar nuevas oportunidades que podrían generarse por la crisis del COVID-19 y sus impactos en cascada. 
1 Diseñar acciones y estrategias de políticas innovadoras y con visión de futuro. La prospectiva puede ayudar a generar nuevas ideas y direcciones sobre la mejor manera de promover los objetivos sociales y el bienestar global al desafiar y expandir nuestras percepciones de lo que es posible en el futuro.

\section{- B Bibliografía}

Bolívar, J. (2015). Investigación Documental. México. Pax.

Castro, J. (2016). Técnicas Documentales. México. Limusa.

Davila, A. (2015). Diccionario de Términos Científicos. .Caracas: Editorial Oasis.

Gautret, P., Lagier, C., Parola, P., Hoang, \& VT. (2020). Hydroxychloroquine and azithromycin as a treatment of COVID19: results of an open-label non-randomized clinical trial. Int J Antimicrobial Agent .

King, S. (2020). Perspective Covid-19 and the Need for Health Care Reform. New England.

Luisetto, M., Rafa, Y., Edbey, K., \& Mashori, R. (2020). Epidemiology and diffusion of some relevant virus: latitude, air pollutants and humidity role. Hypothe- sis of work: covid 19 effect on the air pollution in some world region: what implications. J Toxicology and Risk Assessment. , 1-13.

McKee, M., Stuckler, \& D. (2020). If the world fails to protect the economy, COVID-19 will damage health not just now but also in the future. Nature Medicine , 640-642.

Ogen, Y. (2020). Assessing nitrogen dioxide (NO2) levels as a contributing factor to coronavirus (COVID-19) fatality. Science of Total Environment , 726.

Olombi, D., Petrini, M., \& Maffi, G. (2020). Well aerated lung on admitting chest CT to predict adverse outcome in covid -19 pneumonia. Radiology , 321329.

Organizacion Mundial del Comercio. (3 de Abril de 2020). Desplome del comercio ante la pandemia de COVID-19, que está perturbando la economía mundial. Recuperado el 24 de Agosto de 2020, de https://www.wto.org/spanish/news_s/pres20_s/ pr855_s.htm

Ozili, K., \& Thankom, A. (2020). Spillover of COVID-19: Impact on the Global Economy.

Zhaoa, M. (2020). Cytokine storm and immunomodulatory therapy in COVID-19: Role of chloroquine and anti-IL-6 monoclonal antibodies. Int J Antimicrob Agents.

\section{CITAR ESTE ARTICULO:}

Pazmiño Gavilánez, W., Merchán Jacome, V., \& Jiménez Rendon, E. (2020). Planificación estratégica y su impacto ante la crisis del Covid-19. RECIAMUC, 4(3), 167-182. doi:10.26820/reciamuc/4.(3).julio.2020.167-182 